\title{
Localized Prostate Cancer in Patients Under the Age of 60
}

\author{
Akim Kogui Douro' ${ }^{1 *}$, Khalid Lmezguidi ${ }^{2,3}$, Youness Boukhlifi ${ }^{1}$, Arnaud Tayiri ${ }^{1}$, Abdellatif \\ Janane $^{1}$, Ahmed Ameur ${ }^{1}$ and Mohamed Alami ${ }^{1}$ \\ ${ }^{1}$ Department of Urology, Military Teaching Hospital in Rabat, Morocco
}

${ }^{2}$ Faculty of Medicine, Mohamed V University, Rabat, Morocco

${ }^{3}$ military hospital Lâ̂youne, morocco

*Corresponding author: Akim Kogui Douro, Urology Department of the Mohamed V Military Hospital in Rabat, Mohamed

V- University, Morocco

\begin{tabular}{|c|c|}
\hline ARTICLE INFO & ABSTRACT \\
\hline Received: 幽 January 11, 2021 & $\begin{array}{l}\text { Citation: Akim Kogui Douro, Khalid Lmezguidi, Youness Boukhlifi, Arnaud Tayiri, } \\
\text { Abdellatif Janane, Ahmed Ameur, Mohamed Alami. Localized Prostate Cancer in Patients }\end{array}$ \\
\hline Published: 㓞 January 20, 2021 & Under the Age of 60. Biomed J Sci \& Tech Res 33(2)-2021. BJSTR. MS.ID.005376. \\
\hline
\end{tabular}

\section{Introduction}

Prostate cancer (PCa) remains the second cause of cancer death in men, it is a public health problem especially in elderly patients with $35.5 \%$ cases diagnosed after 75 years. it is rare before the age of 60 with 9\%. The risk factors for PCa are the age melanoderm ethnicity and a family history of $\mathrm{PCa}$, in which case they occur five to ten years earlier than in the general population [1,2]. The heterogeneity of its genetic an environmental factor, make this cancer an uncertain prognosis and its real incidence in young men is difficult to assess because most men of this age do not have screening, and varies according to countries, ethnicity and age [1-4]. The Screening of Pca is based on digital rectal examination (DRE) and rate of the prostate specific antigen (PSA) [5-7]. Since the use of PSA as a test for Pca, more and more young men are diagnosed in the early stages of the disease [5,6]. Few published data regarding PCa in young men have reported conflicting results. Some have suggested that PCa in young men has a better prognosis than that in older men, while others have reported an unfavorable prognosis $[7,8]$.

Radical prostatectomy (RP) remains the standard treatment for localized PCa, reducing mortality by 10 to $15 \%$ at 10 years, through its efficacy in terms of cancer control and increased overall survival [9-11]. Through the study 20 cases of localized PCa in patients under 60 years treated by RP carried out in the urology department of the military teaching hospital of Rabat and a review of the different published series, we propose to analyze the particularities of this cancer in this age group.

\section{Materials and Methods}

This is a retrospective study including all patients treated for localized PCa by RP and whose age is less than 60 years at the Mohamed V Military teaching Hospital in Rabat between January 2004 and October 2014.To analyze the particularities of localized PCa in patients aged less than 60 years, we were interested in the following parameters: age, diagnostic circumstances, PSA level, extension assessment, TNM stage, preoperative and postoperative clinical and pathological evaluation. The data were collected by an exhaustive search in the medical files, radiological, operative and anatomopathological reports available in the archives of the urology department of mohamed V military teaching hospital. The statistical analyzes were carried out using software Microsoft Office Excel.

\section{Results}

\section{Clinical Results}

Age: The average age at the time of diagnosis was 55.5 years, with extremes of age 47 years and 59 years. The age groups are distributed as follows: $65 \%$ between 50 and 55 years old, and $5 \%$ are 50 years old (Figure 1 ).

A. Reasons for Consultation: most often they are voiding disorders such as dysuria and pollakiuria, found in $70 \%$ of cases and $30 \%$ of patients have been asymptomatic (Figure 2). 


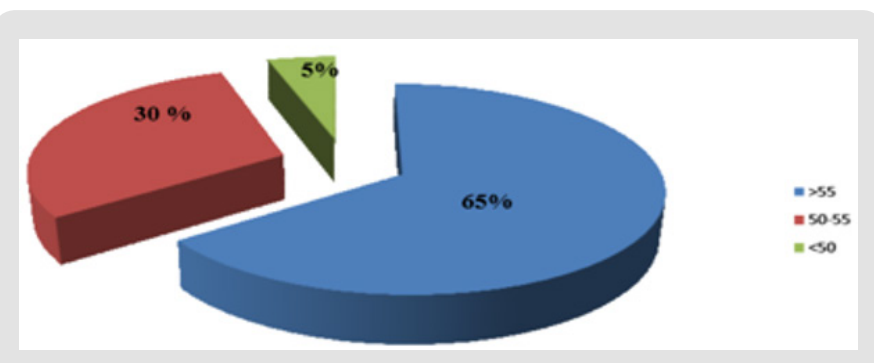

Figure 1: Distribution of patients according to age groups.

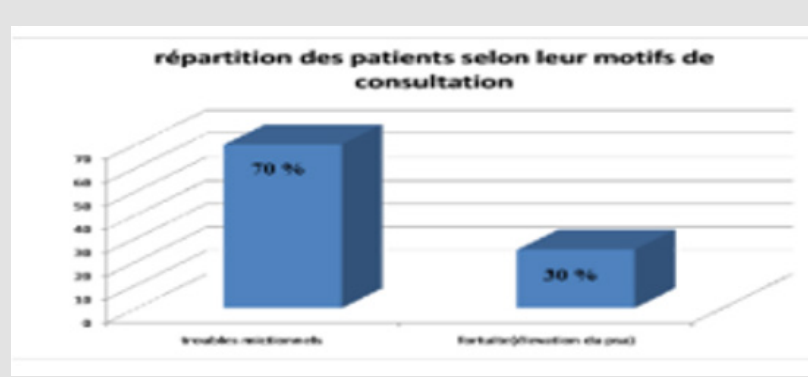

Figure 2: Distribution of patients according to their reason for consultation.

\section{Digital Rectal Examination (DRE)}

The DRE was considered normal by the urologist in $80 \%$ of the cases, and 4 patients presented with induration or a palpable prostate nodule with the DRE (Figure 3). The results of the paraclinical examinations for diagnostic purposes:

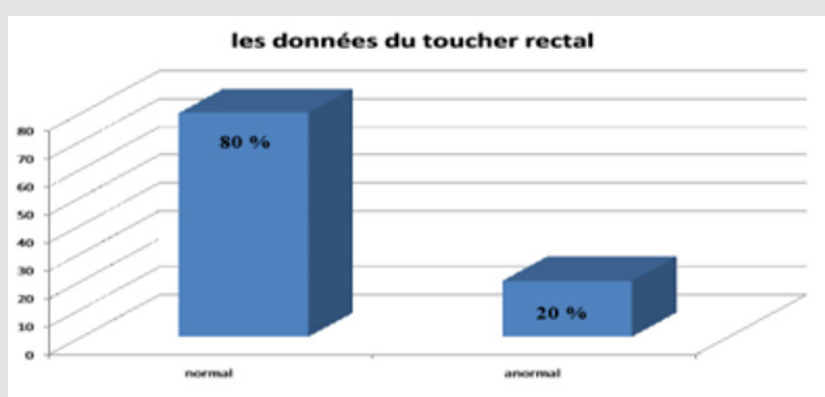

Figure 3: The rectal exam data.

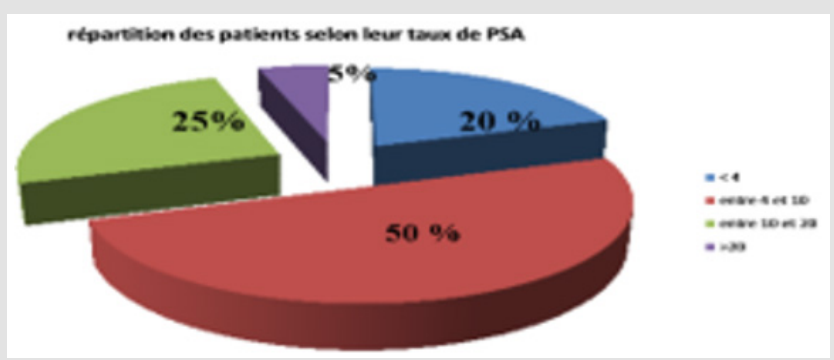

Figure 4: Distribution of patients according to their PSA levels.

The Prostate Specific Antigen (PSA): The mean PSA level was $9.8 \mathrm{ng} / \mathrm{ml}$ (1.26-44.34 ng / ml. The prevalence of CaP located in the PSA section $<10 \mathrm{ng} / \mathrm{ml}$ was $20 \% .70 \%$ of patients treated with PRP had PSA $<10$, however the rest of the patients (30\%) had PSA $>10$ ng / ml, including 1 with PSA> 20ng / ml (Figure 4).

Analysis of the prostate biopsy data (Table 1) reveals that the majority of localized CaPs diagnosed in this series:

a. $\quad 80 \%$, by an extensive biopsy (12> carrots).

b. The number of positive carrots per patient was $<3$

c. in $75 \%$ of cases and $>3$ in 4 patients

while the diagnosis in 1 patient was obtained on the histological data of the TURP. adenocarcinoma was found in all patients. The biopsy Gleason score was $<7$ in $80 \%$ of cases, equal to 7 in $15 \%$ of cases and $>7$ in $5 \%$ of cases. The percentage of invasion of positive biopsies was also evaluated, it varied between 0 to $80 \%$, with an average of $41.25 \%$.Peri-nervous sheathing was found in $40 \%$ of the cases (Table 1).

Table 1: Data from the localized CaP biopsy.

\begin{tabular}{|c|c|c|}
\hline \multicolumn{3}{|c|}{ Type of Biopsy: } \\
\hline \multicolumn{2}{|c|}{16} & Percentage\% \\
\hline$>12$ carottes & 3 & 15 \\
\hline$<12$ carottes & 15 & 75 \\
\hline \multicolumn{3}{|c|}{ Carottes positives: } \\
\hline$<3$ & 4 & 20 \\
\hline$>3$ & 16 & 80 \\
\hline$<7$ & 3 & 15 \\
\hline$>7$ & 1 & 5 \\
\hline$>7$ & 8 & 40 \\
\hline Perineal deception & & \\
\hline
\end{tabular}

\section{The Results of the Extension Assessment}

Magnetic Resonance Imaging: Carried out in 14 patients $(70 \%)$, most of the patients had a tumor. limited to the organ without lymph node extension. The extra capsular extension was noted in one patient (5\%).

Bone Scintigraphy: There was suspicion of a secondary lesion in one patient and CT scan with a bone window helped to correct the diagnosis and rule out the metastatic nature of this lesion, which was in fact arthritis (Table 2). After the extension assessment, the most frequent stage was the T2b stage present in 30\% of the patients, followed by the T1c, T2a and T2c stages present in 15\% of the patients for each, the T1a and T1b stages present in two patients, then stage T3a present in a single patient which represents $5 \%$ of the sample studied. All patients were classified as N0.

Table 2: Results of bone scintigraphy.

\begin{tabular}{|c|c|c|}
\hline & Effective & Percentage \% \\
\hline Not Done & 3 & 15 \\
\hline Normal & 16 & 94.4 \\
\hline
\end{tabular}




\begin{tabular}{|c|c|c|}
\hline Suspicious lesions & 1 & 5.6 \\
\hline Total & 20 & 100 \\
\hline
\end{tabular}

According to D'Amico criteria, the CaP located in our series was located in a low-risk group ( $\leq \mathrm{T} 2 \mathrm{a}$ and $\mathrm{G} \leq 6$ and PSA $<10$ ) in $25 \%$ of cases, at intermediate risk ( $\mathrm{T} 2 \mathrm{~b}$ or $\mathrm{G}=7$ or $10<\mathrm{PSA} \leq 20$ ) in $45 \%$ of cases, and at high risk (T2c or G> 7 or PSA $>20$ ) in 30\% of cases (Figure 5 \& 6).

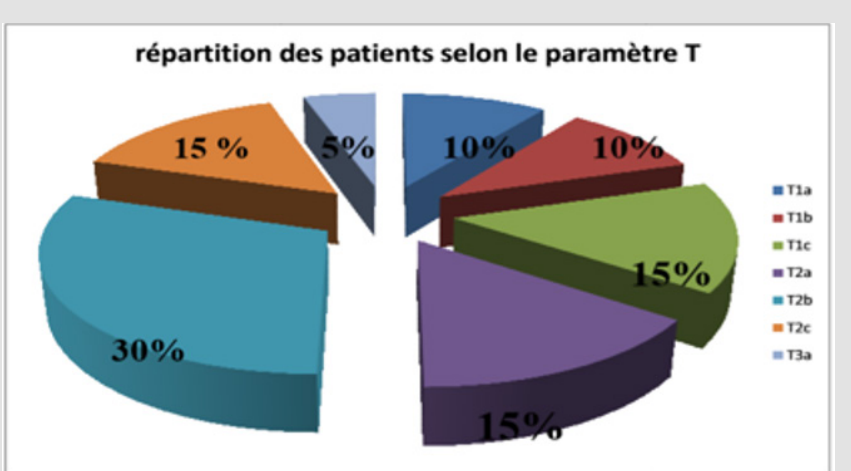

Figure 5: Distribution of patients according to parameter T of the TNM classification.

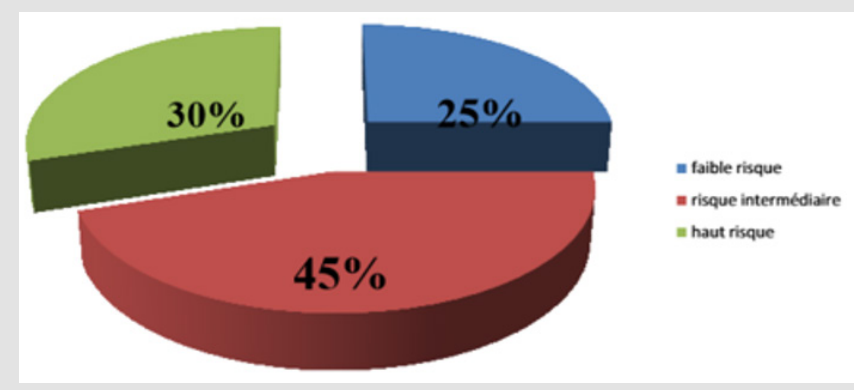

Figure 6: Distribution of patients according to AMICO classification.

\section{Therapeutic Choice}

Radical Prostatectomy: the standard treatment of localized PCa in patients with a life expectancy greater than 10 years. Classically reserved for organ-confined tumors, RP can also be considered for tumors with limited extra-capsular extension (clinical T3a, biopsy or MRI), partly young patients. In our series, all patients underwent radical public prostatectomy with lymph node dissection and preservation of the two neurovascular bundels in 15 cases, right unilateral in 3 cases, left unilateral in 2 cases.

\section{Pathology Results of the Operating Specimen}

The correlation between the clinical data (stage cT and GS) and those of the pathological study prostate specimen was identical in $15 \%$ of the cases for the stages cT - pT and $80 \%$ of the cases for the Gleason scores (SGb SGp) (Figure 7). upstaging of the Gleason stage and / or grade to a higher level was observed in $75 \%$ and $15 \%$ of the cases, respectively. Downward migration of the Gleason stage or grade was observed in $10 \%$ and $5 \%$ of cases respectively. When we analyze more closely the cases of upgrading from the clinical stage to the (15 patients) (Figure 8) We find that the progression of the stage occurred in the same group of low risk $(\leq \mathrm{Pt} 2 \mathrm{~b})$. However, in the rest of the cases (80\%), we only moved to a high-risk group ( $\geq$ pT2c). Upgrading from an organ-confined stage ( $\leq \mathrm{cT} 2 \mathrm{c}$ ) to a locally advanced stage (pT3a-b) was observed in 5 patients.

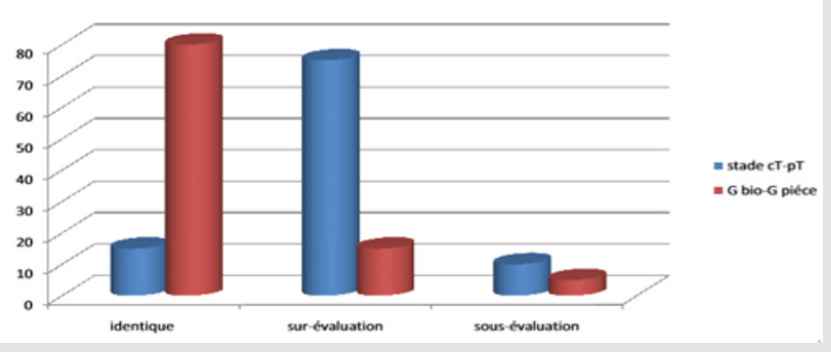

Figure 7: Correlation between the clinical data and those of the anatomopathological examination.

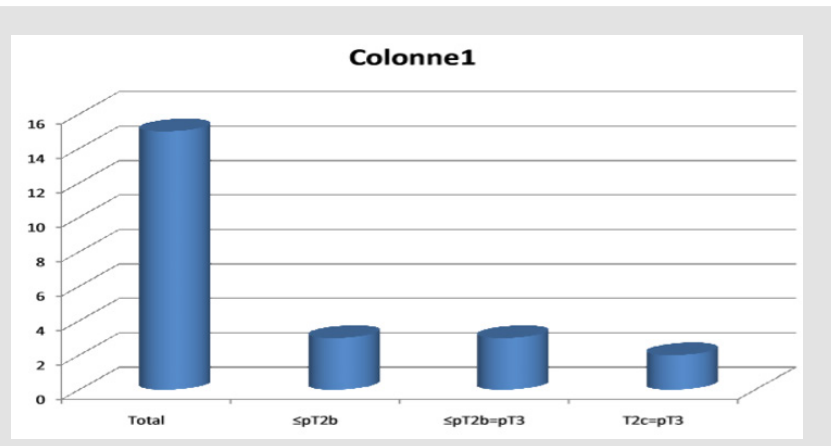

Figure 8: Upward migration of the clinical stage after RP.

'A downgrading of the clinical stage on the PRR part was observed in two patients, the two patients initially evaluated cT2c, were pT2a. Regarding the upgrading of the biopsy Gleason score and grade on prostate surgical specimen ( 3 patients): only 1 patient had a significant prognostic migration of the Gleason score ( $\mathrm{SGp} \geq 7$ ). In the rest of the cases, the migration of the Gleason grade was done in the same prognosis group, not eliminating the advantage of performing a RP.

\section{Adjuvant Therapy}

The rate of positive surgical margins in our series was $25 \%$. In the 5 patients, the surgical margins were focal and very limited (R1), The status of surgical margins is one of the major factors of biological recurrence which determines whether or not an adjuvant treatment is necessary after surgery. The attitude in our service is to monitor patients (PSA) and treat only in the event of a biological recurrence (PSA $>0.2 \mathrm{ng} / \mathrm{ml}$ confirmed at two successive dosages). In our series 2 patients had benefited from external radiotherapy Combined with short-term hormone therapy, and one patient received hormone therapy alone. 


\section{Post-Operative Monitoring and Evaluation}

Marked by a Biological and Clinical Evaluation: On the biological level, the PSA dosage made it possible to judge the oncologic results at a distance from the intervention and found at 1 month three patients had a PSA $>0.2 \mathrm{ng} / \mathrm{ml}$, at 3 months only one patient had a PSA equal to $0.2 \mathrm{ng} / \mathrm{ml}$, at 6 months the PSA was undetectable and at 12 months a patient 1 patient had increased his PSA. On the clinical level, the postoperative evaluation in the 9 patients still followed at the time of this work, had shown 1 case of absence of erection: 1 case of urinary incontinence, 1 case of nocturia.

\section{Discussion}

Prostate cancer is a real public health problem by its frequency, with great variability in incidence and mortality worldwide. The incidence of prostate cancer varies by more than 25 times worldwide, and according to GLOBOCAN 2012, Morocco has been classified in the zone where the incidence varies between 10.8 and 19.5 / 100,000 [12,13]. Some studies preceding the era of PSA use have estimated the incidence of $\mathrm{CaP}$ in young men to be between 0.8 and $4 \%$. The actual incidence of young subjects is difficult to assess in the general population, since most men of this age do not have screening. Mortality rates are generally high in the predominantly black populations, According to GLOBOCAN 2012 Morocco has been classified in the area where mortality varies between 10 and 13.9 / 100,000. In our series, the average age at diagnosis was 55.5 years, with extremes of 47 and 59 years of age [14,15]. The age groups are distributed as follows: $65 \%$ of patients are over 55 years of age, $30 \%$ between 50 and 55 years of age, and $5 \%$ are under 50 years of age.

The circumstances of discovery are often during a screening by PSA or following the appearance of urinary disorders, $70 \%$ of our patients were already symptomatic and screening was done following urinary disorders of the lower urinary tract. The discovery of cancer was fortuitous during an individual screening in $30 \%$ of our patients, this rate does not exceed $6 \%$ in the study by Amégbor, et al. and Reached $15 \%$ in the study by Filella, et al. and $18 \%$ in the study by BALLA, et al. (HMIV in 2009). The TR has a positive predictive value estimated between $21 \%$ and $53 \%$, In our series the TR was considered normal by the urologist in $80 \%$ of the cases and that 4 patients presented a induration or a palpable prostate nodule at the TR. Active surveillance as a therapeutic option is reserved for requesting patients who have a localized tumor with a very good prognosis.

Active surveillance leads to the identification of the most aggressive forms, to delaying treatment for a few years and thereby delaying the date of onset of urinary and sexual complications from treatment. However, active surveillance has not yet been validated as an alternative to immediate treatment in young men $[16,17]$. Total prostatectomy is one of the benchmark treatments for CaP localized in patients whose life expectancy, estimated by age and associated poly-pathologies, is greater than or equal to 10 years [18-20]. External radiotherapy is a validated alternative to total prostatectomy, with similar carcinological results in the medium term [22-27]. In young men, few studies are available concerning external radiotherapy for CaP [22-25]. Rosser, et al. [24] compared the results of external radiotherapy in 98 patients under the age of 60 and 866 older patients in one study and this concluded that young age thus appears to be a factor in poor prognosis [22-24].

Brachytherapy is an alternative to total prostatectomy for tumors with a low risk of progression, its carcinological results at 12 years are similar to those of total prostatectomy. Few data have been published regarding prostate cancer ( $\mathrm{CaP}$ ) in young men. In addition, the few studies that have analyzed the prognosis of $\mathrm{CaP}$ in this population have resulted in conflicting results [28].

\section{Carcinological Results}

In 1995, an American study analyzed the impact of age on survival without biological recurrence after total prostatectomy [29]. The rate of biological recurrence was significantly lower in young patients than in older patients. The study by Magheli et al. [30], including very young patients 435 patients aged 45 or less were compared to three other age groups 70: 46-55 years, 56-65 years and above or equal to 66 years. The number of patients has made it possible to conclude that the impact of age on the cancer outcome of patients remains uncertain, due to the lack of large prospective controlled studies. Total prostatectomy seems to have at least equivalent results in terms of effectiveness in young patients compared to an older population.

\section{Functional Results}

Age in itself represents, outside of any surgical context, a predictor of incontinence by sphincter insufficiency and a predictor of erectile dysfunction by vascular obstruction. This remains true after total prostatectomy. An American team retrospectively compared the results of total prostatectomy in 66 young patients and 724 older patients. Surgical complications and rates of biological recurrence were similar between the two groups. Among patients who had bilateral vasculo-nervous preservation, $100 \%$ of young patients versus $81.4 \%$ of older patients had satisfactory postoperative erections without or with treatment (phosphodiesterase-5 inhibitor or cavernous injections). Even if the rare retrospective series published are based on an imperfect methodology, it appears that young age is associated with less urinary and sexual sequelae of the intervention. This notion is well known in current practice.

Young patients are less likely to experience severe postoperative urinary incontinence and permanent loss of their erections than elderly patients. A prospective analysis of clinical data from 2334 patients who underwent a prostate biopsy in the urology 
department of the H.M.I.M. V between January 2000 and December 2008:

\section{The Indications for the Prostate Biopsy were}

a total PSA level $\geq 4 \mathrm{ng} / \mathrm{ml}$ regardless of the digital rectal examination.

\section{Conclusion}

The PCa of the young man does not have characteristics different from that of the older man. Young age does not seem to influence the oncologic results of the different treatments. On the other hand, young men seem to have less risk of severe urinary and sexual complications, especially after RP. There are no specific recommendations for the management of PCa in young men. a localized PCa, two options can be conceived, the first option is to want to limit the urinary and sexual complications of radical prostatectomy. treatment such as brachytherapy, or even active surveillance, can meet this objective. The second option, on the contrary, consists in being more "aggressive" from the outset, given the usual long-life expectancy. Offering a total prostatectomy makes it possible to reserve for the patient the possibility of adjuvant or remedial radiotherapy in the event of locally advanced disease or local recurrence.

\section{References}

1. Jawad EL-AZHARI (2009) Prostate cancer at the Mohamed V Military Hospital: epidemiological profile, clinical-histological and therapeutic aspects (about 568 cases). these n pp.199.

2. Brawley OW, Knopf K, Merrill R (1998) The epidemiology of prostate cancer part I: descriptive epidemiology. Semin Urol Oncol 16: 187-192.

3. Valeri A, Moineau MP, Azzouzi AR, Cormier L, Baschet F, et al. (2008) Étude française sur le dépistage du cancer de la prostate dans les familles à risque : bilan à 5ans dans le groupe 40-49 ans. Prog Urol 18: 736.

4. Carter HB, Allaf ME, Partin AW (2007) Diagnosis and staging of prostate cancer. Campbell-Walsh Urology. Philadelphia: Saunders Elsevier pp. 2912-2931

5. Villers A, Pommier P, Bataillard A, Fervers B, Bachaud JM, et al. (2001) Standards, options et recommandations pour la prise en charge des patients atteints de cancer de la prostate non métastatique. Janvier.

6. Catalona WJ, Smith DS, Ratliff TL, Dodds KM, Coplen DE, et al. (1991) Measurement of prostate-specific antigen in serum as a screening test for prostate cancer. N Engl J Med 324: 1156-1161.

7. Riopel M, Polascik T, Partin A, et al. (1995) Radical prostatectomy in men less than 50 years old. Urol Oncol 1: 80-83.

8. Magheli A, Rais-Bahrami S, Humphreys EB, HJ Peck, Bruce JT, et al. (2007) Impact of patient age on biochemical recurrence rates following radical prostatectomy. J Urol 178(5): 1933-1938.

9. Moran PS, O’Neill M, Teljeur C, Flattery M, Murphy LA, et al. (2013) Robot- assisted radical prostatectomy compared with open and laparoscopic approaches: A systematic review and meta- analysis. Int J Urol 20(3): 312-321.

10. Shikanov S, Woo J, Al- Ahmadi H, Katz MH, Zagaja GP, et al. (2009) Extrafascial versus interfascial nerve- sparing robotic assisted laparoscopic radical prostatectomy: comparison of functional outcomes and positive surgical margins characteristics. Urology 74(3): 611-616.
11. Marien T, Sankin A, Lepor H (2009) Factors predicting preservation of erectile function in men undergoing open radical retropubic prostatectomy. J Urol 181(4): 1817-1822.

12. Cochran JS, Kadesky MC (1981) A private practice experience with adenocarcinoma of the prostate in men less than 50 years old. J Urol 125: 220-221.

13. Huben R, Natarajan N, Pontes E, Mettlin C, Smart CR, et al. (1982) Carcinoma of prostate in men less than fifty years old. Data from American College of Surgeons' National Survey. Urology 20(6): 585-588.

14.(2012) Fichier des tumeurs et estimations et projections démographiques, ministère de la santé et des services sociaux. Plan commun de surveillance produit par l'infocentre de santé publique à l'Institut national de santé publique du Québec. Mise à jour de l'indicateur.

15. Klotz L (2004) Active surveillance with selective delayed intervention: using natural history to guide treatment in good risk prostate cancer. J Urol 172(5): S48-50.

16. Dall'era MA, Konety BR, Cowan JE (2008) Active surveillance for the management of prostate cancer in a contemporary cohort. Cancer 112 : $1650-1659$.

17. Bill-Axelson A, Holmberg L, Filen F (2008) Radical prostatectomy versus watchful waiting in localized prostate cancer: the Scandinavia prostate cancergroup-4 randomized trial. J Natl Cancer Inst 100: 1144-1154.

18. Moran PS, O’Neill M, Teljeur C, Flattery M, Murphy LA, et al. (2013) Robot- assisted radical prostatectomy compared with open and laparoscopic approaches: A systematic review and meta- analysis. Int J Urol 20(3): 312-321.

19. Shikanov S, Woo J, Al- Ahmadi H, Katz MH, Zagaja GP, et al. (2009) Extrafascial versus interfascial nerve- sparing roboticassisted laparoscopic radical prostatectomy: comparison of functional outcomes and positive surgical margins characteristics. Urology 74(3): 611-616.

20. Marien T, Sankin A, Lepor H (2009) Factors predicting preservation of erectile function in men undergoing open radical retropubic prostatectomy. J Urol 181(4): 1817-1822.

21. Kupelian PA, Elshaikh M, Reddy CA (2002) Comparison of the efficacy of local therapies for localized prostate cancer in the prostatespecific antigen era: a large single-institution experience with radical prostatectomy and external-beam radiotherapy. J Clin Oncol 20: 33763385 .

22. Nguyen TD, Poortmans PM, Van den Hulst M, O Thomas, Marco K, et al. (2005) The curative role of radiotherapy in adenocarcinoma of the prostate in patients under 55 years of age: a rare cancer network retrospective study. Radiother Oncol 77(3): 286-289.

23. Rosser CJ, Chichakli R, Levy LB, DA Kuban, LG Smith, et al. (2002) Biochemical disease-free survival in men younger than 60 years with prostate cancer treated with external beam radiation. J Urol 168(2): 536-541.

24. Park SS, McGrath S, Ghilezan M (2008) Impact of young age on clinical outcome in prostate cancer treated with high-dose RT in the modern era. Int J Radiat Oncol Biol Phys (72).

25. Brenner DJ, Curtis RE, Hall EJ (2000) Second malignancies in prostate carcinoma patients after radiotherapy compared with surgery. Cancer 88(2): 398-406

26. Nieder AM, Porter MP, Soloway MS (2008) Radiation therapy for prostate cancer increases subsequent risk of bladder and rectal cancer: a population based cohort study. J Urol 180(5): 2005-2009.

27. Sharkey J, Cantor A, Solc Z, W Huff, Stanley DC, et al. (2005) 103Pd brachytherapy versus radical prostatectomy in patients with clinicallylocalized prostate cancer: a 12- year experience from a single group practice. Brachytherapy 4(1): 34-44. 
28. Twiss C, Slova D, Lepor H (2005) Outcomes for men younger than 50 years undergoing radical prostatectomy. Urology 66(1): 141-146.

29. Magheli A, Rais-Bahrami S, Humphreys EB, Hugh JP, Bruce JT, et al. (2007) Impact of patient age on biochemical recurrence rates following radical prostatectomy. J Urol 178(5): 1933-1938.

\section{ISSN: 2574-1241}

DOI: 10.26717/BJSTR.2021.33.005376

Akim Kogui Douro. Biomed J Sci \& Tech Res

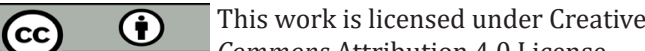

Submission Link: https://biomedres.us/submit-manuscript.php
30. Twiss C, Slova D, Lepor H (2005) Outcomes for men younger than 50 years undergoing radical prostatectomy. Urology 66(1): 141-146.

$\begin{array}{ll}\text { BIOMEDICAL } & \text { Assets of Publishing with us } \\ \text { RESEARCHES } & \text { - Global archiving of articles } \\ \text { - Immediate, unrestricted online access } \\ \text { - Rigorous Peer Review Process } \\ \end{array}$

